\title{
New race and ethnicity standards: elucidating health disparities in diabetes
}

\author{
Peter T Katzmarzyk ${ }^{*}$ and Amanda E Staiano
}

\begin{abstract}
The concepts of race and ethnicity are useful for understanding the distribution of disease in the population and for identifying at-risk groups for prevention and treatment efforts. The U.S. Department of Health and Human Services recently updated the race and ethnicity classifications in order to more effectively monitor health disparities. Differences in chronic disease mortality rates are contributing to race and ethnic health disparities in life expectancy in the United States. The prevalence of diabetes is higher in African Americans and Hispanics compared to white Americans, and parallel trends are seen in diabetes risk factors, including physical inactivity, dietary patterns, and obesity. Further research is required to determine the extent to which the observed differences in diabetes prevalence are attributable to differences in lifestyle versus other characteristics across race and ethnic groups.
\end{abstract}

Keywords: diabetes, race, ethnicity, health disparities, chronic disease, physical inactivity, dietary patterns, obesity

\section{Introduction}

'Distinctive racial or ethnic patterns of disease can be profitably applied by the public health official to the detection and prevention of disease and by the clinician in diagnosis and treatment.' Albert Damon, 1969 [1] p.79

Overall life expectancy at birth has increased steadily in the United States from 47 years in 1900 to 78 years in 2007 [2]. The increase in life expectancy has resulted from improvements in public health (for example sanitation, infectious disease control, food security) and the prevention and treatment of medical conditions. However, there remain significant racial gaps [2,3]. In 2007, white Americans could expect to live 4.8 years longer than African Americans under current mortality patterns [2].

A major public health goal in the United States is to achieve health equity, eliminate disparities, and improve the health of all groups by 2020 [4]. A total of $51 \%$ and $64 \%$ of the racial gap in life expectancy in men and women, respectively, is attributable to differences in mortality rates from diabetes, cardiovascular disease, and cancer [3]. Indeed, diabetes is the eighth and fourth leading

\footnotetext{
* Correspondence: peter.katzmarzyk@pbrc.edu

* Correspondence: peter.katzmarzyk@pbrc.edu
Population Science, Pennington Biomedical Research Center, 6400 Perkins Road, Baton Rouge, LA 70808, USA
}

cause of death among white and African Americans, respectively [5]. Thus, efforts to reduce racial disparities in health should focus on understanding and reducing differences in the rates of chronic diseases such as diabetes.

There is considerable regional variation in the prevalence of diabetes at the global level; however, the overall prevalence is high and continues to increase [6]. Regional differences in the prevalence of diabetes are undoubtedly the result of complex interactions among socioeconomic forces, lifestyle factors, and genetic predisposition. Given that race and ethnic disparities are often viewed within a country-specific context, the focus of this discussion is on the United States.

\section{Concepts of race and ethnicity}

Race and ethnicity are interrelated concepts that have a long history in the fields of human biology and public health $[1,7]$. Although the terms are often used interchangeably in the literature and there are no widely accepted definitions, race and ethnicity tend to have distinct meanings. Race is typically used to refer to groups that share biological similarities, whereas ethnicity refers to shared cultural similarities. In many cases, race and ethnic groups may overlap considerably; however, race and ethnicity are useful concepts when attempting to 
understand differential health risks and health disparities $[8,9]$.

The Institute of Medicine [10] reported that inadequate data on race and ethnicity lowered the likelihood of effective actions to address health disparities. In response, the Department of Health and Human Services recently updated standards to more consistently measure race and ethnicity and thereby improve the ability to monitor improvements in health disparities (Table 1) [11]. These new race and ethnic categories expand upon the current Office of Management and Budget (OMB) classifications that are often used in research [12]. The use of the new categories will allow for the more precise identification of health risks in specific race and ethnic groups, and could translate into more individualized treatment regimens for the prevention and management of diabetes in the future.

\section{Racial and ethnic differences in diabetes prevalence}

Diabetes affects an estimated 20.4 million adults (9.6\%) in the U.S., of which 19\% are undiagnosed [13]. However, the age-adjusted prevalence of total diabetes (diagnosed and undiagnosed) differs by race and ethnicity, as African Americans (14.9\%) and Mexican Americans (15.6\%) had approximately double the prevalence as white Americans (7.6\%) [13] in the 2003-2006 U.S. National Health and Nutrition Examination Survey (NHANES). Ethnic disparities are also evident in the number of medically diagnosed diabetes cases identified in the 2008 National Health Interview Survey, in which the age-adjusted prevalence of diagnosed diabetes for adults was $11.0 \%$ in African Americans, 10.7\% in Hispanics, $8.2 \%$ in Asians, and $7.0 \%$ in whites [14]. The higher prevalence of diabetes among African Americans and Hispanics translates into a higher lifetime risk of developing diabetes than in white Americans (Figure 1) [15].

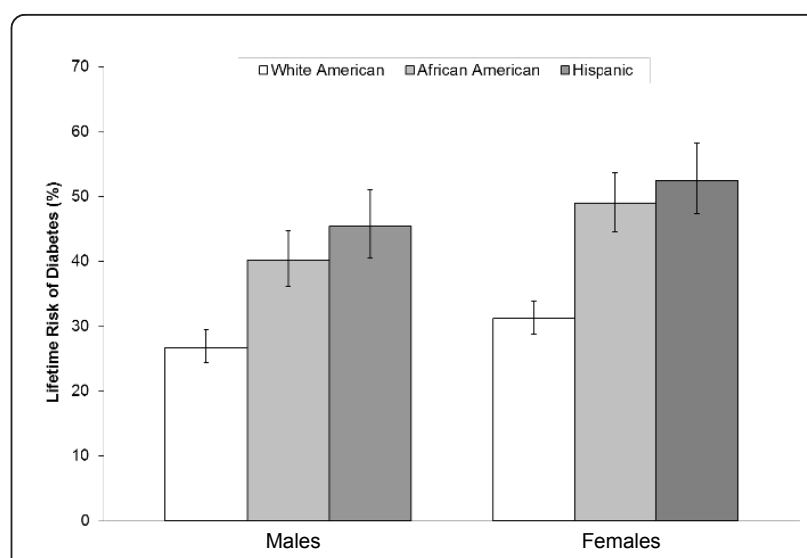

Figure 1 Lifetime risk (\%) of developing diabetes in the United States among individuals born in $\mathbf{2 0 0 0}$. Adapted from results presented in Narayan et al. [15]. Error bars indicate 95\% confidence intervals.

Race and ethnic differences in diabetes prevalence persist across different subgroups of the population. For example, among adults aged 65 years and over, $32.7 \%$ of African Americans, $31.8 \%$ of Mexican Americans, and $18.8 \%$ of white Americans have diagnosed or undiagnosed diabetes [13]. Few cases of diabetes are reported in youth; however, the prevalence of type 2 diabetes is twoto three-fold higher among American-Indian and African American youth compared to Asian/Pacific Islander and Hispanic youth, and nine-fold higher than in white youth [16]. Among immigrants to the U.S., diabetes prevalence increases as length of residence increases, independent of age or body mass index [17]. There is also evidence that risk factors such as physical inactivity and obesity differ according to length of residence in other Western countries such as Canada $[18,19]$.

Table 1 New categories of race/ethnicity established by the U.S. Department of Health and Human Services [11]

\begin{tabular}{ll}
\hline Race & Ethnicity \\
\hline - White & - Not of Hispanic, Latino/a, or Spanish origin \\
- American Indian or Alaska Native & - Hispanic Mexican, Mexican American, or Chicano/a \\
- Asian Indian & - Hispanic Puerto Rican \\
- Chinese & - Hispanic Cuban \\
- Filipino & - Other Hispanic, Latino, or Spanish origin \\
- Japanese & \\
- Korean & \\
- Vietnamese & \\
- Other Asian & \\
- Native Hawaiian & \\
- Guamanian or Chamorro & \\
- Samoan & \\
- Other Pacific Islander & \\
\hline
\end{tabular}


Diabetes, ethnicity, and race: the role of lifestyle factors and socioeconomic status

\section{Physical inactivity}

Physical inactivity is an important risk factor for the development of diabetes [20]. Based on data from the 2005 U.S. Behavioral Risk Factor Surveillance System (BRFSS), African Americans and Hispanics had lower levels of leisuretime physical activity than white Americans [21]. These racial and ethnic differences in self-reported leisure-time physical activity appear to begin in adolescence [22]. On the other hand, based on objectively-measured (accelerometry) data from NHANES 2003-2004, Mexican American adults had higher physical activity levels compared to African Americans and white Americans [23]. Further, Mexican Americans were also less sedentary $(<100$ accelerometer activity counts/min) than white or African Americans across the lifespan, while white and African Americans had similar levels of sedentary behavior [24]. The discrepant race and ethnic differences observed for self-reported versus objective methods are difficult to explain. The differences could be due to cultural influences in the reporting of physical activity, or the different aspects of human movement captured by the two methods: the accelerometry used in NHANES captures total ambulatory physical activity, including leisure-time, occupational, and domestic (such as chores) domains, whereas the BRFSS questionnaire captures information on leisuretime physical activity only.

\section{Dietary patterns}

A healthy dietary pattern has been linked to a reduced risk of developing diabetes [25]. For example, the consumption of red meat is associated with a higher risk of diabetes [26], and the intake of leafy green vegetables is associated with a lower risk [27]. Among adults from the Lower Mississippi Delta region of the U.S, whites had a higher Healthy Eating Index (HEI) as well as higher component scores for grains, vegetables, milk, and variety than African Americans [28]. Results from successive waves of NHANES (from 1971 to 2002) indicate that differences in dietary patterns between white and African Americans, such as the higher energy density of foods consumed among African Americans, have persisted over time [29]. These results suggest that race differences in dietary patterns may be significant; however, more research is required to better delineate the extent of the differences and their potential impact on health.

\section{Obesity}

Obese individuals have 20 to 50 times greater risk of developing diabetes than people who are normal weight $[30,31]$. The estimated lifetime risk of developing diabetes from the age of 18 years in the U.S. increases from $19.8 \%$ and $17.1 \%$ for normal weight (body mass index (BMI) $18.5-24.9 \mathrm{~kg} / \mathrm{m}^{2}$ ) men and women to $70.3 \%$ and $74.4 \%$ for men and women with a BMI $\geq 35 \mathrm{~kg} / \mathrm{m}^{2}$, respectively [32]. The prevalence of obesity differs across race and ethnic groups in the U.S. The most recent data from the 2007-2008 NHANES indicates that the ageadjusted prevalence of obesity (BMI $\geq 30 \mathrm{~kg} / \mathrm{m}^{2}$ ) was $32.4 \%$ in whites, $37.9 \%$ in Hispanics, and $44.1 \%$ in African Americans, and these differences are consistent in men and women (Figure 2) [33].

The degree to which race and ethnic groups differ in absolute risk for incident diabetes at a given level of body fatness has not been clearly delineated. After controlling for body weight, diabetes prevalence was more than twice as high among African Americans and Latinos compared to white Americans in a U.S. cohort [34]. Few studies have employed prospective designs to study racial differences in the relationship between obesity and diabetes. Data from the Atherosclerosis Risk in Communities (ARIC) Study indicated that the incidence of diabetes over a 9-year period was higher at all levels of BMI in African Americans compared with white adults [35]. This is in contrast to results from the NHANES Epidemiologic Follow-up Study in which the 20-year incidence of diabetes was higher in African Americans than white Americans at low BMI values, but equivalent at higher BMI values [36]. More research is required to understand the differential risks for diabetes related to obesity across race and ethnic groups.

\section{Socioeconomic status}

Race and ethnic disparities in diabetes prevalence may be confounded by socioeconomic inequalities. On average, African Americans and Hispanics tend to be poorer and less educated [37] and less likely to have health insurance [38], compared to white Americans. In the U. S. National Health Interview Survey, diabetes prevalence was highest among individuals with low educational attainment and those below the federal poverty line

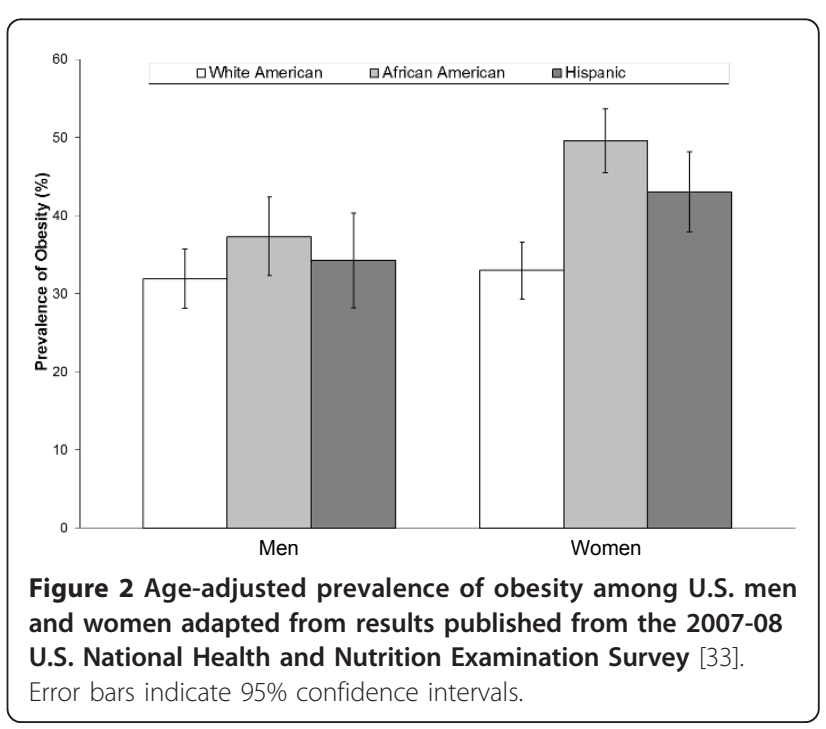


[14]. Disparity in diabetes prevalence due to income and education increased from 2004 to 2008, whereas race/ ethnic disparities in diabetes prevalence and incidence did not change [14]. There was little race/ethnic difference in diabetes prevalence among a cohort of African American and white adults of similar low socioeconomic status from the southern U.S., except a moderately higher rate in African American versus white women [39]. Because socioeconomic status is a potentially modifiable factor, interventions to prevent diabetes could focus on improving social circumstances and access to care among the less educated and impoverished [40].

\section{Conclusions}

The concepts of race and ethnicity are useful in understanding the distribution of diabetes and related risk factors in the population. Data from representative surveys from the U.S. have demonstrated significant race and ethnic differences in the prevalence of diabetes and parallel differences in lifestyle risk factors. This mounting evidence for race and ethnic differences may indeed prove profitable both in understanding the epidemiology of diabetes and in targeting at-risk groups for prevention and treatment efforts. However, further research is required to determine the extent to which the disparities in diabetes risk are attributable to differences in lifestyle versus other characteristics that cluster within race and ethnic groups, such as differences in genetics or metabolism.

The new, more precise categories of race/ethnicity will allow investigators and clinicians to better understand disparities and to create individualized or group-specific treatment plans that target the individuals most at risk for the development of diabetes and related complications. Although the role of lifestyle factors in explaining race and ethnic differences has not been fully delineated, the adaptation of current physical activity and dietary guidelines for use in different ethnic and race groups could prove beneficial to prevention efforts. In addition, prevention and treatment efforts could target lifestyle factors that are known to be disproportionately higher or lower in specific race/ethnic groups.

\section{List of abbreviations}

ARIC: Atherosclerosis Risk in Communities; BMI: body mass index; BRFSS: U.S. Behavioral Risk Factor Surveillance System; HEl: Healthy Eating Index; NHANES: U.S. National Health and Nutrition Examination Survey; OMB: Office of Management and Budget.

\section{Acknowledgements}

PTK is supported, in part, by the Louisiana Public Facilities Authority Endowed Chair in Nutrition. AES is supported, in part, by the National Institutes of Health National Research Service Award.

\section{Authors' contributions}

PTK and AES researched the literature and drafted the manuscript. Both authors approved the final version.

\section{Authors' information}

PTK is Associate Executive Director for Population Science, Professor and Louisiana Public Facilities Authority Endowed Chair at Pennington Biomedical Research Center. AES is a Postdoctoral Research Fellow in the Division of Population Science at Pennington Biomedical Research Center.

\section{Competing interests}

The authors declare that they have no competing interests.

Received: 9 December 2011 Accepted: 30 April 2012

Published: 30 April 2012

\section{References}

1. Damon A: Race, ethnic group, and disease. Soc Biol 1969, 16:69-80

2. U.S. Department of Health and Human Services, Centers for Disease Control and Prevention, National Center for Health Statistics: Health, United States, 2010. With Special Feature on Death and Dying. Hyattsville, MD: NCHS Office of Information Services; 2011

3. Harper S, Lynch J, Burris S, Davey Smith G: Trends in the black-white life expectancy gap in the United States, 1983-2003. JAMA 2007, 297:1224-1232.

4. Healthy People 2020 Framework: The Vision, Mission, and Goals of Healthy People 2020. [http://www.healthypeople.gov].

5. Centers for Disease Control and Prevention: Racial/ethnic disparities in prevalence, treatment and control of hypertension - United States, 1999-2000. Morb Mortal Wkly Rep (MMWR) 2005, 54:7-9.

6. Katzmarzyk PT, Barreira TV, Harrington DM, Staiano AE, Heymsfield SB, Gimble JM: Relationship between abdominal fat and bone mineral density in white and African American adults. Bone 2012, 50:576-579.

7. Comstock RD, Castillo EM, Lindsay P: Four-year review of the use of race and ethnicity in epidemiologic and public health research. Am J Epidemiol 2004, 159:611-619.

8. Winker MA: Measuring race and ethnicity: why and how? JAMA 2004, 292:1612-1614.

9. Karter AJ: Race and ethnicity: vital constructs for diabetes research. Diabetes Care 2003, 26:2189-2193.

10. Institute of Medicine: Race, ethnicity and language data: Standardization for health care quality improvement. Washington, DC: National Academies Press; 2009.

11. Data Collection Standards for Race, Ethnicity, Sex, Primary Language, and Disability Status. [http://minorityhealth.hhs.gov/].

12. Office of Management and Budget: Standards for the Classification of Federal Data on Race and Ethnicity.[http://www.whitehouse.gov/omb/ fedreg_race-ethnicity].

13. Cowie CC, Rust KF, Byrd-Holt DD, Gregg EW, Ford ES, Geiss LS, Bainbridge KE, Fradkin JE: Prevalence of Diabetes and High Risk for Diabetes Using A1C Criteria in the U.S. Population in 1988-2006. Diabetes Care 2010, 33:562-568.

14. Beckles GL, Zhu J, Moonesinghe R: Diabetes - United States, 2004 and 2008. Morb Mortal Wkly Rep (MMWR) 2011, 60:90-93.

15. Narayan KM, Boyle JP, Thompson TJ, Sorensen SW, Williamson DF: Lifetime risk for diabetes mellitus in the United States. JAMA 2003, 290:1884-1890.

16. SEARCH for Diabetes in Youth Study Group, Liese AD, D'Agostino RB Jr, Hamman RF, Kilgo PD, Lawrence JM, Liu LL, Loots B, Linder B, Marcovina S, Rodriguez B, Standiford D, Williams DE: The burden of diabetes mellitus among US youth: prevalence estimates from the SEARCH for Diabetes in Youth Study. Pediatrics 2006, 118:1510-1518.

17. Newman SC: Formulae for cause-deleted life tables. Stat Med 1987, 6:527-528.

18. Barreira TV, Harrington DM, Staiano AE, Heymsfield SB, Katzmarzyk PT: Body adiposity index, body mass index, and body fat in white and black adults. JAMA 2011, 306:828-830.

19. Tremblay MS, Pérez C, Ardern Cl, Bryan S, Katzmarzyk PT: Obesity, overweight and ethnicity. Health Reports 2005, 16:23-34.

20. Jeon CY, Lokken RP, Hu FB, van Dam RM: Physical activity of moderate intensity and risk of type 2 diabetes: a systematic review. Diabetes Care 2007, 30:744-752.

21. Centers for Disease Control and Prevention: Prevalence of regular physical activity among adults - United States, 2001 and 2005. JAMA 2007, 299:30-32. 
22. Centers for Disease Control and Prevention: Youth Risk Behavior Surveillance - United States, 2009. Surveillance Summaries June 4, 2010. Morb Mortal Wkly Rep (MMWR) 2009, , Suppl 5: 1-142.

23. Troiano RP, Berrigan D, Dodd KW, Masse LC, Tilert T, McDowell M: Physical activity in the United States measured by accelerometer. Med Sci Sports Exerc 2008, 40:181-188

24. Matthews CE, Chen KY, Freedson PS, Buchowski MS, Beech BM, Pate RR, Troiano RP: Amount of time spent in sedentary behaviors in the United States, 2003-2004. Am J Epidemiol 2008, 167:875-881.

25. Esposito K, Kastorini CM, Panagiotakos DB, Giugliano D: Prevention of type 2 diabetes by dietary patterns: A systematic review of prospective studies and meta-analysis. Metab Syndr Relat Disord 2010, 8:471-476.

26. Pan A, Sun Q, Bernstein AM, Schulze MB, Manson JE, Willett WC, Hu FB: Red meat consumption and risk of type 2 diabetes: 3 cohorts of US adults and an updated meta-analysis. Am J Clin Nutr 2011, 94:1088-1096.

27. Carter P, Gray LJ, Troughton J, Khunti K, Davies MJ: Fruit and vegetable intake and incidence of type 2 diabetes mellitus: systematic review and meta-analysis. BMJ 2010, 341:C4229.

28. McCabe-Sellers BJ, Bowman S, Stuff JE, Champagne CM, Simpson PM, Bogle ML: Assessment of the diet quality of US adults in the Lower Mississippi Delta. Am J Clin Nutr 2007, 86:697-706.

29. Kant AK, Graubard BI, Kumanyika SK: Trends in black-white differentials in dietary intakes of U.S. adults, 1971-2002. Am J Prev Med 2007, 32:264-272.

30. Chan JM, Rimm EB, Colditz GA, Stampfer MJ, Willett WC: Obesity, fat distribution, and weight gain as risk factors for clinical diabetes in men. Diabetes Care 1994, 17:961-969.

31. Colditz GA, Willett WC, Stampfer MJ, Manson JE, Hennekens CH, Arky RA, Speizer FE: Weight as a risk factor for clinical diabetes in women. Am J Epidemiol 1990, 132:501-513.

32. Narayan KM, Boyle JP, Thompson TJ, Gregg EW, Williamson DF: Effect of BMI on lifetime risk for diabetes in the U.S. Diabetes Care 2007, 30:1562-1566.

33. Flegal KM, Carroll MD, Ogden $C L$, Curtin LR: Prevalence and trends in obesity among US adults, 1999-2008. JAMA 2010, 303:235-241.

34. Maskarinec G, Grandinetti A, Matsuura G, Sharma S, Mau M, Henderson BE, Kolonel LN: Diabetes prevalence and body mass index differ by ethnicity: The Multiethnic Cohort. Ethn Dis 2009, 19:49-55.

35. Stevens J, Couper D, Pankow J, Folsom AR, Duncan BB, Nieto FJ, Jones D, Tyroler HA: Sensitivity and specificity of anthropometrics for the prediction of diabetes in a biracial cohort. Obes Res 2001, 9:696-705

36. Resnick HE, Valsania P, Halter JB, Lin X: Differential effects of BMI on diabetes risk among black and white Americans. Diabetes Care 1998, 21:1828-1835

37. Beckles GL, Truman Bl: Education and income: United States, 2005 and 2009. Morb Mortal Wkly Rep 2011, 60:13-18.

38. Moonesinghe R, Zhu J, Truman Bl: Health insurance coverage - United States, 2004 and 2008. Morb Mortal Wkly Rep 2011, 60:35-37.

39. Signorello LB, Schlundt DG, Cohen SS, Steinwandel MD, Buchowski MS, McLaughlin JK, Hargreaves MK, Blot WJ: Comparing diabetes prevalence between African Americans and whites of similar socioeconomic status. Am J Public Health 2007, 97:2260-2267.

40. Link CL, McKinlay JB: Disparities in the prevalence of diabetes: Is it race/ ethnicity or socioeconomic status? Results from the Boston Area Community Health (BACH) survey. Ethn Dis 2009, 19:288-292.

\section{Pre-publication history}

The pre-publication history for this paper can be accessed here: http://www.biomedcentral.com/1741-7015/10/42/prepub

doi:10.1186/1741-7015-10-42

Cite this article as: Katzmarzyk and Staiano: New race and ethnicity standards: elucidating health disparities in diabetes. BMC Medicine 2012 10:42.

\section{Submit your next manuscript to BioMed Central and take full advantage of:}

- Convenient online submission

- Thorough peer review

- No space constraints or color figure charges

- Immediate publication on acceptance

- Inclusion in PubMed, CAS, Scopus and Google Scholar

- Research which is freely available for redistribution

Submit your manuscript at www.biomedcentral.com/submit
Biomed Central 